\title{
Fatores associados à qualidade da córnea doada pelo Banco de Olhos do Hospital São Paulo
}

\author{
Factors associated with quality of donated corneas \\ in the Hospital São Paulo Eye Bank
}

Flavio Eduardo Hirai ${ }^{1}$

Consuelo Bueno Diniz Adán²

Elcio Hideo Sato ${ }^{3}$
Trabalho realizado no Departamento de Oftalmologia da Universidade Federal de São Paulo - UNIFESP - São Paulo (SP) - Brasil.

Mestre em Saúde Pública. Pós-graduando do Departamento de Oftalmologia, Instituto da Visão da Universidade Federal de São Paulo - UNIFESP - São Paulo (SP) - Brasil.

${ }^{2}$ Doutora em Medicina. Diretora do Banco de Olhos do Hospital São Paulo, Departamento de Oftalmologia, Instituto da Visão da UNIFESP - São Paulo (SP) - Brasil

${ }^{3}$ Doutor em Medicina. Professor da pós-graduação do Departamento de Oftalmologia, Instituto da Visão da UNIFESP - São Paulo (SP) - Brasil.

Endereço para correspondência: Flavio Eduardo Hirai. Rua Pio XI, 1.095 - São Paulo (SP) CEP 05060-001

Email: fhirai@yahoo.com

Recebido para publicação em 19.04.2008

Última versão recebida em 16.12.2008

Aprovação em 20.12.2008

Nota Editorial: Depois de concluída a análise do artigo sob sigilo editorial e com a anuência das Dras. Diane Ruschel Marinho e Myrna Serapião dos Santos sobre a divulgação de seus nomes como revisoras, agradecemos suas participações neste processo.

\section{RESUMO}

Objetivos: Analisar fatores relacionados com a qualidade morfológica do tecido corneano no Banco de Olhos do Hospital São Paulo (BOHSP) da UNIFESP. Métodos: Estudo retrospectivo de dados do Banco de Olhos do Hospital São Paulo no período de 2001 a 2006. Foram coletados dados de idade, sexo, causa do óbito do doador, tempo entre óbito e enucleação do globo ocular (tempo enucleação), tempo entre enucleação e a preservação do tecido corneano (tempo preservação), meio de preservação utilizado e procedência da córnea. Córneas foram examinadas na lâmpada de fenda e classificadas como "Excelente" ou "Boa" (grupo A) ou como "Regular", "Ruim" ou "Inaceitável” (grupo B). Modelos multivariados de regressão logística foram utilizados para detecção de fatores independentes relacionados à qualidade da córnea. Resultados: Dados de 870 doadores foram analisados. Média \pm desvio padrão de idade no grupo A foi de $40,7 \pm 16,1$ e $56,3 \pm 17,5$ no grupo $\mathrm{B}(\mathrm{p}<0,01)$. Tempo preservação foi significativamente menor no grupo A (5,2 vs. 6,6 horas, p<0,01). Não houve diferença estatisticamente significativa quanto ao sexo $(\mathrm{p}=0,82)$ e tempo enucleação $(\mathrm{p}=0,17)$. Uma maior proporção de traumas foi observada no grupo A $(\mathrm{p}<0,01)$. O meio Optisol foi o mais utilizado para a preservação da córnea e aproximadamente metade das córneas avaliadas foi captada pelo BOHSP. Fatores que apresentaram associação independente e estatisticamente significativa com a qualidade da córnea foram: idade ("Odds ratio" IC 95\%, 1,05 (1,04 - 1,06), para aumento de 1 ano), tempo preservação $(1,05(1,02$ - 1,08), para aumento de 1 hora), procedência $(1,53(1,12-2,09)$, para Outros vs. BOHSP) e a causa de óbito $(2,06$ (1,43 - 2,96), para Doenças crônicas vs. Causas externas). Conclusões: Este estudo demonstrou a existência de fatores independentemente associados à qualidade das córneas captadas pelo BOHSP como idade, tempo entre a enucleação e a preservação, causa do óbito e procedência da córnea. Estudos semelhantes devem ser realizados por outras instituições para determinar quais os fatores em comum que devem ser levados em conta a fim de melhorar cada vez mais a qualidade do tecido ocular oferecidos aos cirurgiões oftalmológicos.

Descritores: Doenças da córnea; Bancos de olhos; Transplante de córnea; Controle de qualidade; Obtenção de tecidos e órgãos; Preservação de órgãos

\section{INTRODUÇÃO}

Bancos de olhos exercem papel fundamental na procura, captação, preservação e distribuição de córneas para transplante. $\mathrm{O}$ aumento da 
demanda de transplantes vem sendo acompanhado pelo rigor no controle de qualidade dos tecidos nos bancos de olhos. Controle de qualidade inicia-se com o processo de seleção de doadores, utilização de técnicas adequadas de enucleação do globo ocular e preservação de córnea e avaliação de parâmetros como sorologia do doador e contagem de células endoteliais. Um dos principais critérios para avaliação da qualidade do tecido corneano é a avaliação biomicroscópica realizada com lâmpada de fenda ${ }^{(1)}$.

Avaliação da córnea nos bancos de olhos é importante para que o cirurgião e seu paciente possam contar com um tecido de qualidade e também como uma tentativa de minimizar complicações como a falência primária ${ }^{(2)}$.

Poucos estudos avaliaram os fatores relacionados com a qualidade morfológica de córneas de bancos de olhos ${ }^{(3-5)}$. Dentre os fatores encontrados em estudos passados estão a idade do doador, o tempo entre óbito e enucleação e preservação $0^{(3-5)}$.

O objetivo deste trabalho foi analisar fatores relacionados com a qualidade morfológica do tecido corneano no Banco de Olhos do Hospital São Paulo.

\section{MÉTODOS}

Estudo retrospectivo de dados do Banco de Olhos do Hospital São Paulo (BOHSP) da Universidade Federal de São Paulo (UNIFESP) no período de 2001 a 2006. Dados foram obtidos dos livros de registros de doações com informações deste período. Foram coletados dados de idade, sexo e causa do óbito do doador de acordo com a Classificação Internacional de Doenças (CID-10), tempo entre óbito e enucleação do globo ocular (tempo enucleação), tempo entre enucleação e a preservação do tecido corneano (tempo preservação), meio de preservação utilizado e procedência da córnea. O tempo entre o óbito e a preservação do tecido (tempo total) foi calculado pela soma dos tempos enucleação e preservação. Enucleação de globos oculares e preservação das córneas foram realizadas por técnicos em banco de olhos treinados.

O BOHSP utiliza critério de avaliação da qualidade das córneas baseado em exame biomicroscópico na lâmpada de fenda. Esse critério se baseia na quantificação de 0 a 4, da presença de arco senil, pterígio, exposição epitelial, defeito epitelial, opacidade subepitelial, infiltrado estromal, edema estromal, estria estromal, cicatrizes, dobras na Descemet, perda de células endoteliais, guttata e reflexo especular (Figura 1). As córneas são classificadas como "Excelente", "Boa", "Regular", "Ruim", ou "Inaceitável" após a análise de dois observadores em dias subsequentes.

Para a análise deste estudo, foram utilizados dados de córneas que apresentaram informação completa sobre a qualidade do tecido após doação de pelo menos um dos olhos. Córneas classificadas como "Excelente" ou "Boa" foram agrupadas no grupo A e as córneas classificadas como "Regular", "Ruim" ou "Inaceitável" foram agrupadas no grupo B. Foi utilizado o olho com melhor avaliação de cada doador.

\begin{tabular}{|c|c|c|c|c|c|c|c|c|c|c|}
\hline \multicolumn{3}{|c|}{ OLHO DIREITO } & \multicolumn{5}{|c|}{ OLHO ESQUERDO } \\
\hline 0 & 1 & 2 & 3 & 4 & ARCO SENIL & 0 & 1 & 2 & 3 & 4 \\
\hline 0 & 1 & 2 & 3 & 4 & PTERÍGIO & 0 & 1 & 2 & 3 & 4 \\
\hline 0 & 1 & 2 & 3 & 4 & EXPOSIÇÃOEPITELIAL & 0 & 1 & 2 & 3 & 4 \\
\hline 0 & 1 & 2 & 3 & 4 & DEFEITOEPITELIAL & 0 & 1 & 2 & 3 & 4 \\
\hline 0 & 1 & 2 & 3 & 4 & OPACIDADE SUBEPITELIAL & 0 & 1 & 2 & 3 & 4 \\
\hline 0 & 1 & 2 & 3 & 4 & INFILTRADOESTROMAL & 0 & 1 & 2 & 3 & 4 \\
\hline 0 & 1 & 2 & 3 & 4 & EDEMA ESTROMAL & 0 & 1 & 2 & 3 & 4 \\
\hline 0 & 1 & 2 & 3 & 4 & ESTRIA ESTROMAL & 0 & 1 & 2 & 3 & 4 \\
\hline 0 & 1 & 2 & 3 & 4 & CICATRIZES & 0 & 1 & 2 & 3 & 4 \\
\hline 0 & 1 & 2 & 3 & 4 & DOBRAS NA DESCEMET & 0 & 1 & 2 & 3 & 4 \\
\hline 0 & 1 & 2 & 3 & 4 & PERDADE CÉLULASENDOTELIAIS & 0 & 1 & 2 & 3 & 4 \\
\hline 0 & 1 & 2 & 3 & 4 & GUTTATA & 0 & 1 & 2 & 3 & 4 \\
\hline 0 & 1 & 2 & 3 & 4 & REFLEXOESPECULAR & 0 & 1 & 2 & 3 & 4 \\
\hline
\end{tabular}

Figura 1 - Modelo da ficha utilizada no Banco de Olhos do Hospital São Paulo (BOHSP) para avaliação da córnea doada na lâmpada de fenda

Se o doador apresentou avaliação idêntica nos dois olhos, o olho direito foi utilizado.

$\mathrm{Na}$ análise estatística foram utilizados os testes t de "Student" e qui-quadrado para comparação de variáveis contínuas e categóricas, respectivamente. Utilizamos também uma variável binária (Grupo B vs. Grupo A) para comparação dos dois grupos corneanos. Modelos multivariados de regressão logística foram utilizados para detecção de fatores independentes relacionados à qualidade da córnea e "odds ratio" foi calculado. Devido à alta correlação entre idade do doador e causa do óbito, esses dois fatores foram analisados em modelos distintos.

Realizamos também uma subanálise para avaliar a influência do agrupamento das córneas nos grupos A e B e da inclusão de doadores com idades "extremas" em nossos resultados.

\section{RESULTADOS}

Oitocentos e setenta doadores apresentaram dados completos de pelo menos uma córnea doada e foram incluídos na análise. Desses, 309 (35,5\%) apresentaram pelo menos uma córnea classificada como "Excelente" ou "Boa".

A tabela 1 mostra as características gerais do total e de cada grupo separadamente. A média \pm desvio padrão de idade no grupo A foi de 40,7 $\pm 16,1$ (4 a 87 anos) e $56,3 \pm 17,5$ no grupo B ( 2 a 94 anos) $(\mathrm{p}<0,01)$. Não houve diferença estatisticamente significante quanto ao sexo, sendo observada uma maior proporção de homens doadores em ambos os grupos. O tempo enucleação também não foi estatisticamente diferente entre os dois grupos. Entretanto, o tempo preservação foi significantemente menor no grupo A (5,2 vs. 6,6 horas, $\mathrm{p}<0,01)$ assim como o tempo total $(9,2$ vs. 10,8 horas, $\mathrm{p}<0,01)$. Analisando as causas de falecimento, observamos que houve uma maior proporção de óbitos por doenças cardiovasculares, do aparelho respiratório e neoplasias entre todos os doadores. Uma maior proporção de traumas foi observada no grupo A $(\mathrm{p}<0,01)$ comparado ao grupo B. O meio Optisol foi o mais utilizado para a preservação da córnea e aproximadamente metade das córneas avaliadas foi captada pelo BOHSP. 


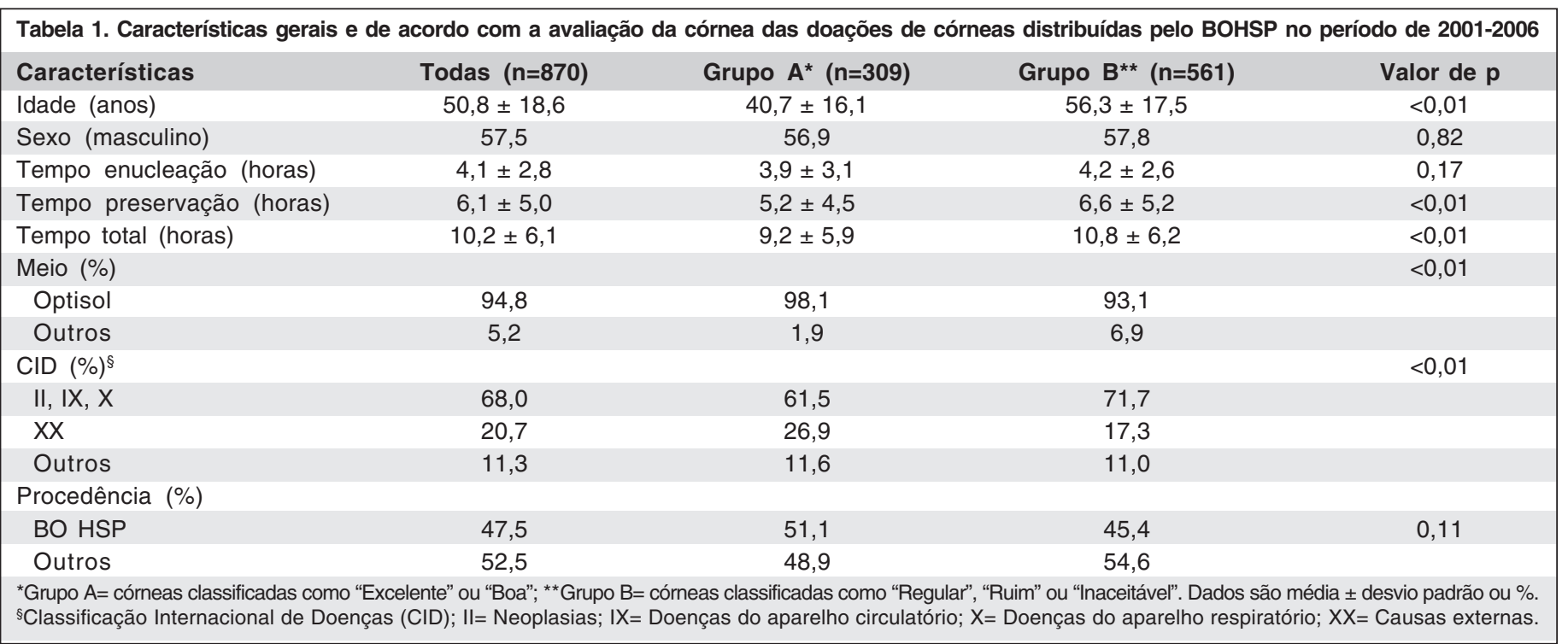

A tabela 2 mostra a avaliação dos fatores associados à qualidade da córnea segundo o modelo multivariado de regresão logística. Os fatores que apresentaram associação independente e estatisticamente significante com a qualidade da córnea foram: idade, tempo preservação, procedência e a causa de óbito. Observamos que a cada 1 ano a mais de idade do doador há uma chance 5\% maior da córnea ser classificada como "Regular", "Ruim" ou "Inaceitável", independentemente de outros fatores como sexo, tempo enucleação, tempo preservação e procedência da córnea ("Odds ratio" (Intervalo de Confiança de 95\%), $1,05(1,04-1,06))$. Observamos situação semelhante quanto ao tempo preservação, em horas $(1,05(1,02-1,08))$. Como o tempo total é decorrente da soma dos tempos enucleação e preservação, optamos pela análise dessas duas variáveis separadamente. Quanto à procedência, as chances de a córnea ser classificada como "Regular", "Ruim" ou "Inaceitável" aumentam em mais de $50 \%$ quando não provenientes do $\operatorname{BOHSP}(1,53(1,12$ - 2,09)). Finalmente, a presença de doenças crônicas aumenta a chance em 2 vezes de classificarmos a córnea como sendo de pior qualidade $(2,06(1,43-2,96))$.

Uma subanálise foi realizada onde as córneas foram reagrupadas em "Excelente", "Boa" e "Regular" e comparadas contra as classificadas como "Ruim" e "Inaceitável". A fim de eliminarmos qualquer influência da dos doadores com idades "extremas", analisamos também a amostra excluindo os doadores abaixo de 10 e acima de 75 anos de idade. Em ambos os casos, os resultados obtidos foram semelhantes ao que obtivemos com a análise inicial (dados não apresentados).

\section{DISCUSSÃO}

Este estudo realizado no BOHSP apresentou resultados semelhantes a estudos realizados no Brasil $^{(5)}$ e em outros países $^{(3-4,6-7)}$.

\begin{tabular}{|c|c|c|}
\hline Variável & OR (IC 95\%) & Valor de $p$ \\
\hline Idade, por 1 ano & $1,05(1,04-1,06)$ & $<0,01$ \\
\hline Sexo, masculino vs. feminino & $1,23(0,90-1,69)$ & 0,18 \\
\hline Tempo enucleação, por 1 hora & $1,02(0,97-1,08)$ & 0,33 \\
\hline Tempo preservação, por 1 hora & $1,05(1,02-1,08)$ & $<0,01$ \\
\hline Procedência, outros vs. BOHSP & $1,53(1,12-2,09)$ & $<0,01$ \\
\hline $\begin{array}{l}\text { CID, Doenças crônicas vs. } \\
\text { Causas externas* }\end{array}$ & $2,06(1,43-2,96)$ & $<0,01$ \\
\hline
\end{tabular}

Farias et al observaram que idade, contagem inicial de células endoteliais $>2.500$ células $/ \mathrm{mm}^{2}$ e causa de óbito que não fosse infecciosa foram associados a melhor qualidade da córnea no primeiro dia de avaliação. Neste trabalho, também foi observado que nenhum destes fatores apresentou associação estatisticamente significante com a mudança na qualidade da córnea durante o período de armazenamento ${ }^{(5)}$.

Idade do doador tem sido fator de controvérsias na literatura científica ${ }^{(3,8-10)}$. Acredita-se que a idade avançada do doador esteja relacionada com uma maior perda de células endoteliais, o que pode comprometer o resultado final dos transplantes. Na maioria dos bancos de olhos, a escolha da idade limite para doação é arbitrária variando entre 60 e 75 $\operatorname{anos}^{(3,10)}$. Estudos mostram que córneas de doadores com idade mais avançadas podem ser perfeitamente aceitáveis para transplante ${ }^{(3,8-9)}$. Alguns autores realizaram um estudo prospectivo de transplantes de córnea e observaram que córneas provenientes de doadores mais velhos (acima de 80 anos) apresentaram menor chance de falência ou rejeição pós-transplante do que córneas de mais jovens ${ }^{(9)}$. Uma possível explicação é o fato de que córneas mais velhas podem apresentar 
uma maior estabilidade quando preservada em cultura de células. Além disso, córneas de doadores mais velhos podem estimular uma menor resposta imunológica do receptor ${ }^{(9)}$. Outros autores estudaram córneas de doadores com idade acima de 75 anos (média de 82,1 anos) e observaram que as córneas que receberam piores avaliações foram as provenientes de doadores previamente submetidos a cirurgia de catarata ${ }^{(3)}$.

O "Cornea Donor Study" investigou a sobrevivência do tecido corneano transplantado em dois grupos de pacientes ${ }^{(11)}$. Um grupo recebeu aleatoriamente córneas de doadores com idade maior ou igual a 66 anos e o outro de doadores com menos de 66 anos. Apesar de córneas provenientes de doadores mais jovens terem apresentado uma menor perda endotelial no pós-operatório ${ }^{(12)}$, não foi observada diferença no resultado final dos transplantes realizados nos dois grupos após 5 anos de seguimento ${ }^{(13)}$. É importante lembrar que neste estudo foram utilizadas córneas com contagem endotelial mínima de 2.300 células $/ \mathrm{mm}^{2} \mathrm{e}$, portanto, não se sabe se doadores mais jovens ou mais velhos com densidade celular endotelial mais baixa apresentariam resultados semelhantes.

Um fator comum observado em vários estudos que influencia na qualidade do tecido foi o tempo entre o óbito e a preservação do tecido. No mesmo estudo com doadores acima de 75 anos, o tempo entre óbito e a enucleação (média 3,5 horas) e tempo entre óbito e preservação (média 10,8 horas) foram fatores significantemente associados com a qualidade da córnea ${ }^{(3)}$. Um outro estudo europeu avaliou doadores com média de idade semelhante ao nosso e também observou uma associação do menor tempo entre o óbito e a preservação com melhor qualidade da córnea ${ }^{(4)}$.

Dentre as explicações para a influência do tempo entre o óbito e enucleação e/ou preservação na qualidade do tecido corneano estão as possíveis alterações metabólicas ou até anatômicas na córnea durante esse período ${ }^{(14)}$. Alguns autores mostraram que o tempo elevado entre o óbito e a enucleação mostrou-se associado com uma perda endotelial mais acentuada em pacientes transplantados ${ }^{(6)}$. Já outros autores observaram que o tempo entre o óbito e a preservação pode estar associado à maior chance de defeito epitelial na córnea. Isso pode aumentar a exposição do tecido a traumas e a toxicidade de substâncias e medicamentos durante o período de preservação, diminuindo sua qualidade para transplante ${ }^{(15)}$.

Outros fatores associados a melhor qualidade da córnea doada em nosso estudo foram a causa de óbito e a proveniência do botão. Quanto à causa de óbito, doadores que tiveram mortes por traumas ou causas externas apresentaram melhor qualidade da córnea doada. Um estudo em córneas mantidas em culturas de células mostrou que córneas provenientes de doadores com morte traumática apresentaram metabolismo intacto enquanto que as provenientes de doadores que morreram de câncer ou insuficiência renal, o metabolismo estava diminuído ${ }^{(14)}$. Entretanto, um outro estudo mostrou que córneas de doadores cuja causa de óbito foi trauma apresentaram maior perda de células endoteliais comparadas a córneas de doadores cuja causa de morte não foi trauma ${ }^{(16)}$. Existe uma correlação entre idade e causa do óbito onde os mais jovens tendem a ter como principais causas os traumas e os mais velhos as doenças cardiovasculares crônicas e neoplasias. Devido a essa associação, é difícil definir se a qualidade da córnea é devido a fatores associados a própria causa de morte ou à idade do doador.

A procedência da córnea também foi um fator independente associado à qualidade da córnea em nosso estudo. Possíveis explicações são o fato de que outros serviços seguem padrões diferentes de captação e preservação do tecido além do fator transporte. Um estudo experimental observou que o transporte não foi um fator deletério para as córneas, mas sim a temperatura em que elas foram mantidas ${ }^{(17)}$. Entretanto, este estudo utilizou córneas porcinas mantidas em meios de cultura de células o que limita a extrapolação dos resultados para a nossa realidade. Uma limitação de nosso estudo é de que não foi possível realizar uma correlação da qualidade da córnea com a contagem de células endoteliais (microscopia especular) pois tais dados não foram coletados para o presente estudo.

\section{CONCLUSÃO}

Nosso estudo demonstrou que fatores como idade, tempo entre a enucleação e a preservação, causa do óbito e procedência estão independentemente associados à qualidade das córneas captadas pelo BOHSP. Estudos semelhantes devem ser realizados por outras instituições para determinar quais os fatores em comum que devem ser levados em conta a fim de melhorar cada vez mais a qualidade do tecido ocular oferecida aos cirurgiões oftalmológicos.

\section{ABSTRACT}

Purpose: To investigate factors associated with the morphological quality of corneal tissue at the Hospital São Paulo Eye Bank (BOHSP) - UNIFESP. Methods: Retrospective study of records from the BOHSP between 2001 and 2006. Information about donors such as age, gender, and cause of death were collected as well as time between death and enucleation (timeto-enucleation), time between enucleation and tissue preservation (time-to-preservation), preservation media, and source of corneal tissue. Biomicroscopic examination was performed in preserved corneas which were classified as "Excellent" or "Good" (group A) or "Regular", "Bad", or "Unacceptable" (group B). Multivariate logistic regression models were used to assess factors that were independently associated with corneal quality. Results: Data from 870 cornea donors were analyzed. The mean \pm standard error age in groups $\mathrm{A}$ and $\mathrm{B}$ was $40.7 \pm 16.1$ and $56.3 \pm 17.5$ years, respectively $(\mathrm{p}<0.01)$. Time-topreservation was significantly lower in group $\mathrm{A}$ (5.2 vs. 6.6 hours, $\mathrm{p}<0.01)$. There was no statistically significant difference between the two groups regarding gender $(\mathrm{p}=0.82)$ and time-to- 
enucleation $(\mathrm{p}=0.17)$. A higher proportion of traumas was observed in group A compared to group B $(\mathrm{p}<0.01)$. Overall, Optisol was the most commonly used preservation medium and approximately half of the corneas were harvested by BOHSP. Factors that were independently associated with corneal quality were: age (Odds ratio 95\% CI, 1.05 (1.04 - 1.06), for 1 year), time-topreservation (1.05 (1.02 - 1.08), for 1 hour), source (1.53 (1.12 2.09), for Others vs. BOHSP) and cause of death (2.06 (1.43 - 2.96), for Chronic diseases vs. External causes). Conclusions: This study showed some factors that were independently associated with morphological quality of donated corneas in the BOHSP such as age, time-to-preservation, source, and cause of death. Similar studies are necessary in order to determine factors that might influence the quality of corneas delivered to ophthalmic surgeons.

Keywords: Corneal diseases; Eye banks; Corneal transplantation; Quality control; Tissue and organ procurement; Organ preservation

\section{REFERÊNCIAS}

1. Sousa LB, Chicani CF, Saud EE, Faria T, Sato EH. Perfil das doações de córneas no Banco de Olhos do Hospital São Paulo. Arq Bras Oftalmol. 1997;60(6):608-16.

2. Hirai FE, Klatte S, Pacini KM, Sato EH. Falência primária pós-transplante de córnea em serviço universitário. Arq Bras Oftalmol. 2002;65(6):655-7.

3. Probst LE, Halfaker BA, Holland EJ. Quality of corneal donor tissue in the greater-than-75-year age group. Cornea. 1997;16(5):507-11.

4. Grabska-Liberek I, Szaflik JP, Brix-Warzecha M. The importance of various factors relating to the morphological quality of corneas used for PKP by the Warsaw Eye Bank from 1996 to 2002. Ann Transplant. 2003;8(2):26-31.

5. Farias RJ, Kubokawa KM, Schirmer M, Sousa LB. Avaliação de córneas doadoras em lâmpada de fenda e microscopia especular durante o período de armazenamento. Arq Bras Oftalmol. 2007;70(1):79-83.
6. Bohringer D, Reinhard T, Spelsberg H, Sundmacher R. Influencing factors on chronic endothelial cell loss characterised in a homogeneous group of patients. Br J Ophthalmol. 2002;86(1):35-8.

7. Wiffen SJ, Nelson LR, Ali AF, Bourne WM. Morphologic assessment of corneal endothelium by specular microscopy in evaluation of donor corneas for transplantation. Cornea. 1995;14(6):554-61.

8. Chu W, Dahl P, O'Neill MJ. Benefits of specular microscopy in evaluating eye donors aged 66 and older. Cornea. 1995;14(6):568-70, 634.

9. Borderie VM, Scheer S, Touzeau O, Vedie F, Carvajal-Gonzalez S, Laroche L. Donor organ cultured corneal tissue selection before penetrating keratoplasty. Br J Ophthalmol. 1998;82(4):382-8.

10. Beck RW, Gal RL, Mannis MJ, Holland EJ, Cavanagh HD, Foulks GN, et al. Is donor age an important determinant of graft survival? Cornea. 1999;18(5): 503-10. Comment in: Cornea. 2000;19(3):412.

11. Sugar A, Gal RL, Beck W, Ruedy KJ, Blanton CL, Feder RS, Hardten DR, Holland EJ, Lass JH, Mannis MJ, O’Keefe MB, Cornea Donor Study Group.. Baseline donor characteristics in the Cornea Donor Study. Cornea. 2005; 24(4):389-96.

12. Cornea Donor Study Investigator Group, Lass JH, Gal RL, Dontchev M, Beck RW, Kollman C, Dunn SP, Heck E, Holland EJ, Mannis MJ, Montoya MM, Schultze RL, Stulting RD, Sugar A, Sugar J, Tennant B, Verdier DD. Donor age and corneal endothelial cell loss 5 years after successfull corneal transplantation. Specular microscopy ancillary study results. Ophthalmology. 2008;115(4):627-32.

13. Cornea Donor Study Investigator Group; Gal RL, Dontchev M, Beck RW, Mannis MJ, Holland EJ, Kollman C, Dunn SP, Heck El, Lass JH, Montoya MM, Schultze RL, Stulting RD, Sugar A, Sugar J, Tennant B, Verdier DD. The effect of donor age on corneal transplantation outcome results of the cornea donor study. Ophthalmology. 2008;115(4):620-26.e6.

14. Redbrake C, Becker J, Salla S, Stollenwerk R, Reim M. The influence of the cause of death and age on human corneal metabolism. Invest Ophthalmol Vis Sci 1994;35(9):3553-6. Comment in: Invest Ophthalmol Vis Sci. 1995; 36(2):259.

15. Van Meter WS, Katz DG, White H, Gayheart R. Effect of death-to-preservation time on donor corneal epithelium. Trans Am Ophthalmol Soc. 2005;103: 209-22; discussion 222-4.

16. Sobottka Ventura AC, Rodokanak-von Schrenk A, Hollstein K, Hagenah M, Bohnke M, Engelmann K. Endothelial cell death in organ-cultured donor corneae: the influence of traumatic versus nontraumatic cause of death. Graefes Arch Clin Exp Ophthalmol. 1997;235(4):230-3.

17. Kustner M, Klug T, Clemens S. [The influence of transport on organ cultured corneas. An experimental study of porcine corneal endothelium]. Ophthalmologe. 2005;102(7):708-14. German. 